\title{
Mucus hypersecretion: a common symptom, a common mechanism?
}

\author{
D.J. Shale, A.A. Ionescu
}

The secretion of mucus is an inherent part of the defence of the airways with the amount of mucus secretion varying with a range of stimuli, including bacteria, particles and chemical irritants [1]. Hypersecretion occurs in many disease states, but is a major clinical and pathological feature in cystic fibrosis (CF) related bronchiectasis, nonCF bronchiectasis, chronic obstructive pulmonary disease and asthma, which are all associated with the considerable activation of the host inflammatory response [2]. In these disorders there is an expansion of the goblet cell population derived from the airways epithelium. Indeed, this response can be seen as an epithelial cell adaptation to injury, which constitutes a limb of the local host defences of the airway, with epithelial cell proliferation, differentiation into goblet cells and the production of pro-inflammatory mediators and growth factors [3-6].

In $\mathrm{CF}$ the quantity and nature of the mucus produced is altered and there are additional effects of the mucopolysaccharide alginate secreted by mucoid strains of Pseudomonas aeruginosa, and host derived inflammatory cells and their contents adding substantially to the raised viscosity of the airways secretions. These changes provide a favourable environment for bacterial growth, shelter for bacteria from the host inflammatory response and may reduce the response to systemic antibiotics in patients with chronic pulmonary infection. Therefore, it is of interest that in this issue of the European Respiratory Journal HAUBER et al. [7] report on mechanisms linking mucus hypersecretion and airways inflammation in $\mathrm{CF}$. The authors report in bronchial biopsies an increased expression of Interleukin-9 (IL-9), IL-9 receptor and human calcium activated chloride channel-1 (hCLCA1) in bronchial epithelial cells of patients with $\mathrm{CF}$ compared with those of healthy subjects. Using a combination of immunocytochemistry and in situ hybridisation the authors demonstrated co-localisation of IL-9, IL-9 receptor, hCLCA1 and mucus glycoproteins to epithelial cells in the bronchial mucosa. They also showed that there was over expression of these products in the mucosa and submucosal glands in the $\mathrm{CF}$ patients. The validity of these findings is supported by an earlier report of the co-localisation of increased expression of IL-9, IL-9 receptor and hCLCA1 in mucus producing cells in nasal polyps and in nasal and sinus mucosal biopsies from patients with $\mathrm{CF}$ compared with healthy subjects [8]. These findings are similar to those in the airways in asthma, both in animal models and patients [3, 6, 9-13].

These findings raise the question of the role of IL-9 and hCLCA1 in mucus hypersecretion and airways inflammation in CF. IL-9 is a T helper (Th) 2 cell derived cytokine and shares some overlapping actions with IL-4 and IL-13, as well

Section of Respiratory and Communicable Diseases, University of Wales College of Medicine, Llandough Hospital, Penarth, UK.

Correspondence: D.J. Shale, Section of Respiratory and Communicable Diseases, University of Wales College of Medicine, Academic Centre, Llandough Hospital, Penlan Road, Penarth CF64 2XX, UK. Fax: 44 02920716416. E-mail: shaledj@cf.ac.uk as being part of the asthma/atopy associated gene cluster $5 q 31-q 33$ on chromosome 5. This area of the genome codes for the production of an heterogeneous group of cytokines, growth factors and receptors with relevance to allergy and includes IL-3, IL-4, IL-5, IL-9, IL-13 and the $\beta$-chain of IL12 , the glucocorticoid receptor, the $\beta_{2}$-adrenergic receptor and granulocyte-macrophage colony stimulating factor [14]. It is interesting to speculate on the basis of these associations that there are common underlying mechanisms in disease states with mucus hypersecretion as a major feature. The mechanism underlying the action of IL-9 is possibly through increased expression of the hCLCAl gene and protein product, which in turn appears to be linked to the upregulation of the MUC5AC gene. The relevance of this observation is that among the eight mucin genes expressed in the adult human lung, the products of MUC5AC and MUC5B occur at a high concentration in airways mucus, though MUC2 and MUC5AC are upregulated by IL-9 directly in human primary lung epithelial cell cultures [3, 15]. There is a range of experimental evidence to support a link between IL-9 and mucus hypersecretion. In mice a similar channel mCLCA3 is expressed in the lungs of the IL-9 transgenic mouse, which constitutively expresses high levels of IL-9 in the lung, and is increased dramatically following the intra-tracheal installation of IL-9 in nontransgenic animals [16]. In human bronchial cell lines expression of hCLCA1, which shares extensive amino acid homology with mCLCA3, is associated with upregulation of MUC5AC [16]. Supporting these observations in patients with $\mathrm{CF}$, in vitro studies and in animals, hCLCA1 has also been related to mucus production in the bronchial epithelium of patients with asthma [9].

Based on the findings of HAUBER et al. [7] it may be speculated that in CF, IL-9 may have an isolated mucus hypersecretory effect separate from atopy related mucus hypersecretion, which is considered to have overlapping mechanistic components due to the common mucus hypersecretory effects of IL-9, IL-4 and IL-13. Could IL-9 be acting in an isolated fashion? This is an important question as it may explain the hypersecretory components of nonallergic airways diseases. There is no certain answer at present other than direct stimulation studies where IL-9 has a direct effect independent of IL-4, IL-13 and tumour necrosis factor- $\alpha[3,4$, 13]. A simple answer is complicated by the fact that IL-9 causes multiple effects on bronchial epithelial cells, including hypertrophy, switching to a goblet cell phenotype, induction of T-cell chemotaxins and possibly the induction of IL-4 and IL-13, effects that can be reversed by anti-IL-9 antibodies in animal models of allergy [3-6, 13, 17]. The complexity of cytokine network effects can be judged from asthma where the Th2 cytokines IL-4, IL-5, IL-9 and IL-13 have been implicated in the induction of airways hyperresponsiveness and eosinophilia, and the upregulation of mucin genes, which enhances the hypersecretory state. In a mouse model there appears to be a dissociation of the different cytokines in 
respect of these effects, with IL-9 still inducing increased mucus production after blockade of IL-4, but not in the presence of IL-13 blockade, suggesting that in the intact animal cooperative activity between these Th2 cytokines is needed for the full phenotypic expression of their effects in the airways [13]. However, goblet cell hyperplasia and mucus hypersecretion induced by IL-9 was particularly intense after mechanical injury to the asthmatic lung [18]. Persistent airways surface infection with an intense inflammatory response in $\mathrm{CF}$ may provide similar injury effects and drive the injury-repair-IL-9-goblet cell hyperplasia pathway in a similar fashion to that in asthma.

Hence, in the context of the current understanding of the regulatory process underlying mucus hypersecretion, the findings of HAUBER et al. [7] support the possibility that similar mechanisms regulating the increased secretion of mucus are active in both asthma and cystic fibrosis. However, this view remains speculative and awaits confirmation and extension of these findings, but it does move forward the understanding of mucus hypersecretion in the human airways in a further disease state. In terms of cystic fibrosis these findings indicate a potentially important component of the host airways defences involved in clinical features and the pathophysiology of cystic fibrosis lung disease. In cystic fibrosis the possible utilisation of alternative chloride channels to cystic fibrosis transmembrane conductance regulator in the airways has been raised previously, but as HAUBER et al. [7] speculate the upregulation of the human calcium activated chloride channel-1 gene may not be advantageous in cystic fibrosis, though precise knowledge of the control of mucus hypersecretion may lead to new and innovative treatments in cystic fibrosis, asthma and chronic obstructive pulmonary disease.

\section{References}

1. Rogers DF. Airway goblet cells: responsive and adaptable front line defenders. Eur Respir J 1994; 7: 1690-1706.

2. Kim WD. Lung mucus: a clinicians view. Eur Respir J 1997; 10: $1655-1662$.

3. Louahed J, Toda $\mathbf{M}$, Jen $\mathbf{J}$, et al. Interleukin-9 upregulates mucus expression in the airways. Am J Respir Cell Mol Biol 2000; 22: 649-656.

4. Reader RJ, Hyde DM, Schelegle ES, et al. Interleukin-9 induces mucous cell metaplasia independent of inflammation. Am J Respir Cell Mol Biol 2003; 28: 644-672.

5. Little FF, Cruikshank WW, Centre DM. IL-9 stimulates release of chemotactic factors from human bronchial epithelial cells. Am J Respir Cell Mol Biol 2001; 25: 347-352.
6. Temann U-A, Geba GP, Rankin JA, Flavell RA. Expression of interleukin 9 in the lungs of transgenic mice causes airway inflammation, mast cell hyperplasia and bronchial hyperresponsiveness. J Exp Med 1998; 188: 1307-1320.

7. Hauber H-P, Tsicopoulos A, Wallaert B, et al. Expression of hCLCA1 in cystic fibrosis is associated with mucus overproduction. Eur Respir J 2004; 23: 846-850.

8. Hauber H-P, Manoukian JJ, Nguyen LHP, et al. Increased expression of interleukin-9, interleukin-9 receptor and the Calcium-activated chloride channel hCLCA1 in the upper airways of patients with cystic fibrosis. Laryngoscope 2003; 113: $1037-1042$.

9. Toda M, Tulic MK, Levitt RC, Hamid Q. A Calcium-activated chloride channel (hCLCA1) is strongly related to IL-9 expression and mucus production in bronchial epithelium of patients with asthma. J Allergy Clin Immunol 2002; 109: 246-250.

10. Ying S, Meng Q, Kay AB, Robinson DS. Elevated expression of interleukin-9 mRNA in the bronchial mucosa of atopic asthmatics and allergen-induced cutaneous latephase reaction: relationships to eosinophils, mast cells and $\mathrm{T}$ lymphocytes. Clin Exp Allergy 2002; 32: 866-871.

11. Dong Q, Louahed J, Vink A, et al. Interleukin-9 induces chemokine expression in lung epithelial cells and baseline airway eosinophilia in transgenic mice. Eur J Immunol 1999; 29: 2130-2139.

12. McLane MP, Haczku A, van de Rijn M, et al. Interleukin-9 promotes allergen induced eosinophilic inflammation and airways hyperresponsiveness in transgenic mice. Am J Respir Cell Mol Biol 1998; 19: 713-720.

13. Temann U-A, Ray P, Flavell RA. Pulmonary overexpression of IL-9 induces Th2 cytokine expression, leading to immune pathology. J Clin Invest 2002; 109: 29-39.

14. Postma DS, Koppelman GH, Meyers DA. The genetics of atopy and airways hyperresponsiveness. Am J Respir Crit Care Med 2000; 162: s118-s123.

15. Chen Y, Thai P, Zhao Y-H, Ho Y-S, DeSouza MM, Wu R. Stimulation of airway mucin gene expression by interleukin (IL)-17 through IL-6 paracrine/autocrine loop. J Biol Chem 2003; 278: 17036-17043.

16. Zhou Y, Dong Q, Louahed J, et al. Characterisation of a Calcium-activated chloride channel as a shared target of Th2 cytokine pathways and its potential involvement in asthma. Am J Respir Cell Mol Biol 2001; 25: 486-491.

17. Cheng G, Arima M, Honda K, et al. Anti-interleukin-9 antibody treatment inhibits airway inflammation and hyperreacticity in mouse asthma model. Am J Respir Crit Care Med 2002; 167: 409-416.

18. Vermeer PD, Harson R, Einwalter LA, Moninger, Zabner J. Interleukin-9 induces goblet cell hyperplasia during repair of human airway epithelia. Am J Respir Cell Mol Biol 2003; 28: 286-295. 